González-González, C. S., García-Holgado, A., \& García-Peñalvo, F. J. (2020). Strategies to introduce gender perspective in Engineering studies: a proposal based on selfdiagnosis. In 2020 IEEE Global Engineering Education Conference (EDUCON), (27-30 April 2020, Porto, Portugal) (pp. 1884-1890). USA: IEEE.

\title{
Strategies to introduce gender perspective in Engineering studies: a proposal based on self- diagnosis
}

\author{
Carina S. González-González \\ Dept. of Computer Engineering and \\ Systems \\ University of La Laguna \\ San Cristóbal de La Laguna, Spain \\ cjgonza@ull.edu.es
}

\author{
Alicia García-Holgado \\ GRIAL Research Group \\ University of Salamanca \\ Salamanca, Spain \\ aliciagh@usal.es
}

\author{
Francisco José García-Peñalvo \\ GRIAL Research Group \\ University of Salamanca \\ Salamanca, Spain \\ fgarcia@usal.es
}

\begin{abstract}
Gender inequality in STEM careers is a global problem and avoid bias in education can be a solution. This paper presents a framework for inclusion of gender perspective in engineering courses. The methodology followed in its design was divided into two phases: the developed of different educational innovation projects and a co-creation workshop. Several instruments have been created and validated, such as questionnaires, canvas model and rubrics. The framework includes elements such as the self-diagnosis and redefinition of curriculum, contents and practices, specific learning outcomes and gender and sex balanced methods and learning environments for equity.
\end{abstract}

Keywords-gender gap, STEM, engineering education, gender perspective, higher education, equality.

\section{INTRODUCTION}

The lack of diversity and gender inequality is a global problem. Although significant progress has been made in recent years, the situation varies from country to country, and differences can also be found between different sectors of society. Due to the androcentric perspective existing in today's society, women have been made invisible, in general, in almost all disciplines, and in particular, their visibility in university education is not taken into account. This inequality is especially visible in the fields of Science, Technology, Engineering, and Mathematics (STEM), both aeademic and professional contexts. Even within STEM careers, the figures are not homogeneous, and there are differences between countries. The recent data of the Spanish Ministry of Education, Culture and Sport shows a decrease $(28 \%)$ on the election of STEM careers in the last years, and this is more pronounced in girls $(33 \%)$ than boys $(26 \%)$ [1].

In engineering, one of the groups with less representation is women, taken into account that there are significant differences between engineering branches and countries. For example, in some Peruvian and Turkish universities [2], there are more women in computer engineering than in Norway or Spain. Making these environments inclusive is to take their needs into account so that they are not excluded.

The European Higher Education Area (EHEA) has involved a complete overhaul of university degrees, providing an excellent opportunity for gender mainstreaming into teaching. However, although gender studies were promoted in Spanish universities at the end of the 20th century, the same has not happened with the incorporation of the principles of equality in the teaching of degrees [3]. Although university students must receive training on equality [4], there is a lack of practical methodological guides on how to introduce these principles into teaching guides and examples of how to carry out educational activities with a gender perspective in different university disciplines.

There are different ways of introducing the gender perspective in higher education, from specific subjects or degrees to a transversal approach, integrating the content of equality in any subject of the curriculum. Also, there are initiatives associated with educational innovation that try to introduce the gender perspective from an innovative point of view $[5,6]$.

Previous research shows that there are gender differences in learning styles and recommends particular teaching methods most desired for female students in STEM [7, 8]. Also, it is possible to find recommendations for the higher education institutions on taking gender differences in learning into account [8]. According to Pawley et al. [9] there are different theories of gender in publications in engineering education, but these theories and designs are not followed for later research on gender. Thus, note the need for a better understanding of gender in engineering education.

According to [10], if females do not feel welcome or included in STEM careers, they cannot identify as part of the career and thus do not have good experiences about STEM interactions and the STEM career pipeline will continue to leak.

Other research has shown that learning experiences, parental support, and role models are critical for girls in the election of STEM studies [11]. In this sense, Kolmos et al. [12] indicate that intrinsic and social motivations are the most important motivational factors for choosing engineering careers. Once women are studying engineering, the practices of teachers can influence the drop out of the career. O'Brien et al. [13] expose that gender stereotypes can bias assessments from professors, fall down women's beliefs of success and performance, noting the stress of stereotype threat.

Other authors claim for taking into account the diversity in engineering courses and put attention to gender [14]. Related to this, some practical actions for inclusion and engineering education have been published by the Royal Academy of Engineering and the UCL Centre for Engineering Education in 2018 [15]. Other practical recommendations have been made by Mills and Gill [16]. These authors proposed strategies for designing and implementing inclusive curricula in engineering, and suggestions for teachers, trying to influence university engineering departments to transform their practices and contents. 
Following the previous research in the area, this paper will present a framework to include the gender perspective in engineering courses through the transformation of specific subjects based on a first self-diagnosis, as a way to support the definition of educational innovation proposals that promote equality in university education.

This article is organized as follows. Section II describes the methodology followed to define the framework, focused mainly on the description of the first phase. Section III presents the co-creation workshop as the second phase of the applied methodology. Section IV presents a framework to include the gender perspective into engineering courses. Finally, the last section summarizes the main conclusions of the proposal.

\section{Methodology}

The framework definition was divided into two phases. The first phase was focused on the definition of the first version of the framework and the second phase was used to test the framework with professors that never was working on introduce co-education at their courses.

Regarding the first phase, the gender perspective was introduced in three subjects of engineering courses through two educational innovations projects at the University of Salamanca and the University of La Laguna. First, in the University of Salamanca, it was carried out the educational innovation project entitled "Inclusion of the gender perspective in the subject of Software Engineering I" (ref. ID2016/084) with the main objective of incorporating the gender perspective in the teaching of Software Engineering [17]. A set of specific objectives were defined, such as:

a) Incorporate activities that promote the gender perspective in the context of Software Engineering.

b) Offer an academic guide that takes into account the gender perspective.

c) Conduct a mixed study on students' perception of the gender gap in technological contexts.

According to these goals, several actions were developed, like:

- Promotion of the presence of women in the number of groups.

- Visibility of the gender gap sharing information on Twitter using a hashtag.

- Development of three workshops to solve problems related to gender issues in the technological field.

- Development of a final project related to the gender gap for promotion of visibility of women in the STEM context.

- Modification of all educational contents and the creation of an initial guide to include the gender perspective in activities.

- Definition of two instruments of evaluation: a pretest and a post-test [18].

The inclusion of the gender perspective in the teaching of Computer Engineering in the case of the University of La Laguna was carried out within the framework of an educational innovation project called "Feminario". The
"Feminario" project had the general objective of constituting a formal platform for the collaborative design of good practices of equality in the teaching-learning process at the University of La Laguna [19].

The inclusion of gender perspective was included in two subjects: web design and human-computer interaction. The project concluded that the methodology created specifically with an inclusive vision focused on people and agile work had excellent results and it is an excellent strategy to introduce the gender perspective in the teams [18].

Both innovation projects carried out in the University of Salamanca and the University of La Laguna, have been used to identify good practices from a gender perspective in engineering courses and to design a proposal of several tools and instruments to support teachers in their classrooms and in the design of innovative educational projects. This first proposal of the identified good practices and tools has been validated with teachers in a second phase through a cocreation workshop.

Thus, this co-creation workshop with professors from different areas in order to pilot different instruments and discuss the ways to introduce the gender perspective depending on the area [20].

The result of both phases allowed to define the framework for gender perspective in engineering courses described in this work.

\section{CO-CREATION WORKSHOP}

The University of Salamanca organizes a teacher training program aimed to improve the teaching activity through the acquisition of skills related to innovation and assessment, with a particular focus on the digital competences. The program is based on the detected needs in the previous academic year. Although the program covers most of the aspects related to teaching at the university level and also the policies and recommendations at national and international levels, there was a lack of training related to equality. In this context, during the 2018-2019 academic year, authors proposed a cocreation workshop titled "Mainstreaming the gender perspective in university teaching". The workshop not only served as a co-creation space to test the framework but also it was the first activity focus on gender equality inside the teacher training program.

The main objectives of the workshop were as follow:

- Educate for equality in the university.

- Incorporate the gender perspective in the curriculum of a subject.

- Promote the development of innovative teaching projects focused on the gender perspective.

- To analyze reflectively the planning and development of university teaching in order to detect gender biases (teaching guides, bibliographic sources, contents, language and examples used, the relationship between professors and students, interaction in the classroom, creation of working groups, reports, etc.)

- Propose strategies to avoid gender bias.

Regarding the contents:

- Introduction to Co-Education. 
- Gender and University.

- Androcentrism and Stereotypes.

- Non-sexist language in teaching (written and oral).
- Methodological proposals to address teaching-learning processes with a gender perspective.

- Practical cases of mainstreaming of the gender perspective in undergraduate subjects.

\section{Elements for the design of co-educational practices}

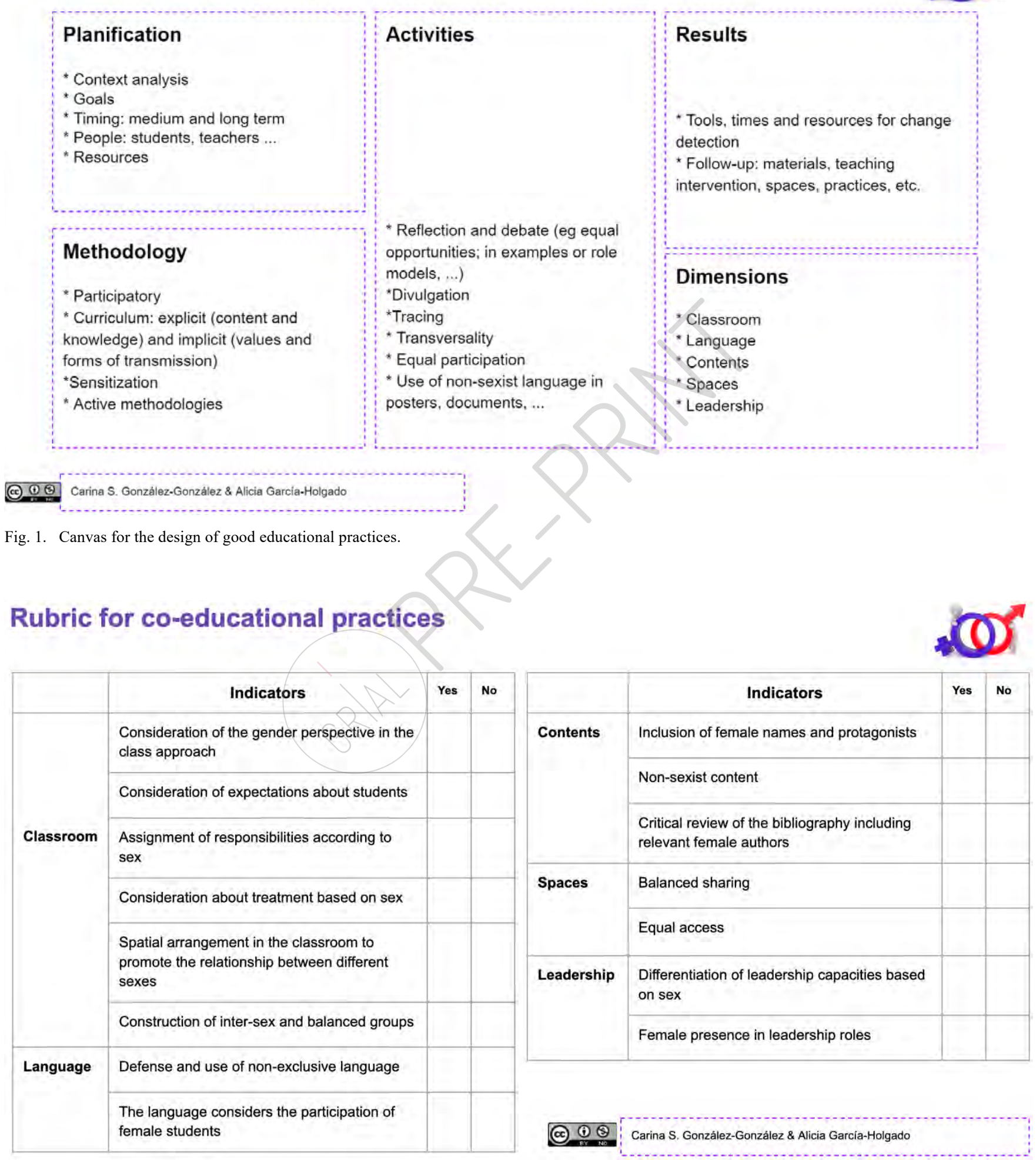

Fig. 2. Rubric for evaluation of good educational practices. 


\section{A. Participants}

The participants involved in the workshop were the professors enrolled through the teacher training program at the University of Salamanca. In particular, the co-creation workshop was made up of 12 participants ( 4 men and 8 women), all of them are professors from the University of Salamanca, with different professional categories: Associate Lecture (1); Research Staff in Training (2); Lecture (3); Senior Lecture (5) and Researcher (1). The teaching staff also belonged to eleven different areas of knowledge: Didactics and School Organization (1); Library Science and Documentation (1); Arab and Islamic Studies (1); Audiovisual Communication and Advertising (1); Nutrition and Food Science (1); Spanish Literature (2); Basic Psychology (1); Evolutionary and Educational Psychology (1); Theoretical Physics (1); Mechanical Engineering (1) and Human Anatomy and Embryology (1). None of the participants used co-education in their courses before attending the workshop.

\section{B. Instruments}

As instruments for the co-creation workshop, a Canvas model was designed with the fundamental elements for the design of educational practices, as well as a rubric with indicators that allowed the analysis of practices (Fig. 1 and Fig. 2). In addition, gamification cards were created to work and review the fundamental concepts of co-education in groups based on the co-educational dictionary (Fig. 3) [21].
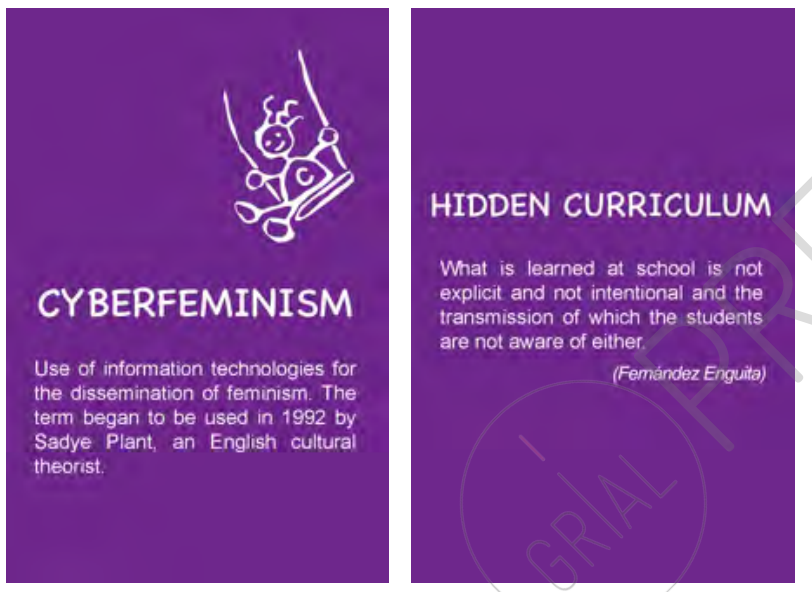

Fig. 3. Example of cards used in the gamified activity based on the coeducational dictionary (Translation into English) [22].

\section{Procedure}

After presenting the fundamental concepts of coeducation, participants worked on the elements that define good educational practices, mainly focused on the key elements of the design of the experience. From what situation it should be started and what point it should be aimed to achieve in the medium and long term; what aspects of equality between men and women should be worked on with greater or lesser intensity; what alternatives for action could be adapted to the specific context, etc.

Likewise, the emphasis was placed on carrying out an analysis for each case on whether they perceived inequality in each of the participants' subjects (in academic performance, in content and materials, in sexist language, in the distribution of tasks, in student attitudes, etc.). In addition, practical advice was given on how participants, as teachers, can introduce the gender perspective into our subjects:
- Examining the contents and materials used within the educational process to avoid including sexist elements, annulling female models, etc.

- Detecting situations of inequality that may occur in the educational space by observing the behavior, attitudes, language, perceptions, and expectations of male and female students with regard to learning, the education received, male and female roles, professional life, their expectations for the future, etc.

- Promoting the empowerment of women by introducing relevant female figures into the contents, encouraging the participation of women and questioning the traditional models of gender relations within the educational space.

- Intervention for the integral development of male and female students on an equal footing.

- Guidelines were also provided for the review of educational content (Fig. 4) and examples of coeducational practices that can be carried out in the classroom, such as:

- Reflecting on equal opportunities.

- Introducing the gender perspective in the examples used, in the role models, etc.

- Involving students to participate equally in the practices.

- Creating posters or documents using non-sexist language.

- Reflecting on and promoting spaces distributed equally, such as sports areas, laboratories, etc.

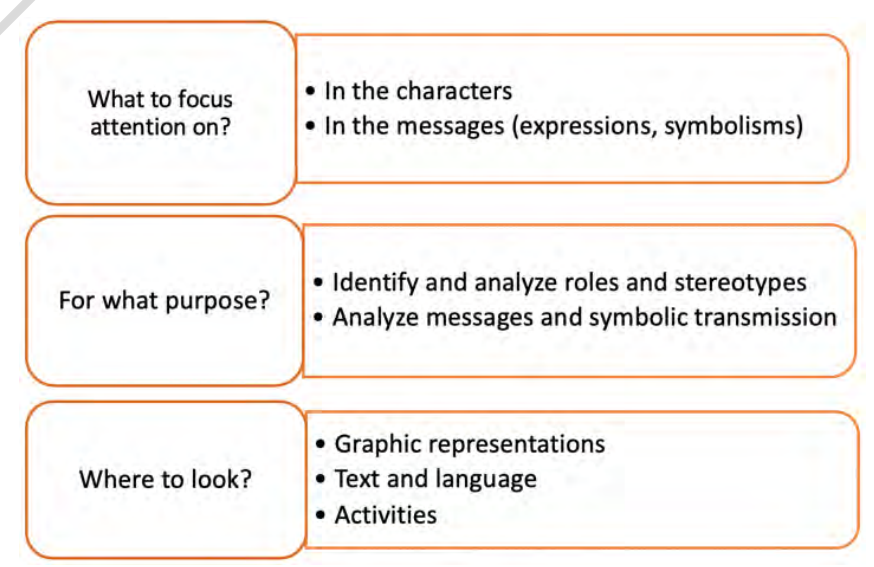

Fig. 4. Guidelines for the review of educational content.

Once the fundamental concepts and guidelines for the design of co-educational experiences were reviewed, the teaching guides for the subjects were reviewed to identify whether or not the indicators of good practice were being met. Then, the teaching guides were modified following the criteria of recognizing the contribution of women in the disciplines, both in the syllabus and in the bibliography. The guide for the use of non-sexist language developed by the University of Salamanca should also be taken into account. Finally, each teacher had to develop at least one activity adapted to the contents of the subject in order to explicitly promote the gender perspective in the learning of the indicated subject. 
Regarding the elaboration of educational innovation projects, different examples developed at the University of Salamanca and at the University of La Laguna were explained. In order to provide a full overview of the work done in the university in which the workshop was conducted, the educational innovation projects of the University of Salamanca were examined in-depth, presenting an analysis of the projects available in the documental repository of the University, Gredos [23]. The analysis showed that only 1.01\% of the projects developed in the last ten years include the term gender in the title or keywords (of 2077 educational innovation projects analyzed in the $2008-2018$ period, only 21 projects include the term gender). Moreover, in the last five years, only 9 projects with the keyword gender have been developed.

Most of the projects found were developed in the areas of Law and Social Sciences, with particular attention to projects related to the Master and the PhD Program in Interdisciplinary Gender Studies. Also, two projects associated with the conference "Equality and youth: detection and analysis of gender violence at university" organized by the Equality Unit were found. Likewise, in Philosophy, a project has been developed to introduce the gender perspective in the analysis of practical cases with the objectives of implementing a transversal model in the analysis of cases with a gender perspective to improve the participation of students and to select audiovisual materials and reports on gender equality and differences as support material. Another project was developed in English Philology to work on intercultural communication competence and gender sensitivity through rap songs in English. Also, in Medicine, a project was developed to work on health aspects from a gender perspective. In Law, it is worth mentioning the project, within the framework of the Master's Degree in Interdisciplinary Gender Studies, focused on developing a workshop for different subjects on how an equality plan is developed and implemented in a company. Finally, a set of educational innovation projects focused on the introduction of the gender perspective in the subject of Software Engineering in the Degree of Computer Science [18-20] was detailed as a practical case, explaining the main barriers encountered, as well as the results of this project.

Regarding the experiences of the University of La Laguna, the FEMINARIO Project was explained to provide a different approach of conducting educational innovation projects across several faculties and areas. Finally, instructions were given for the design of educational innovation projects that include the gender perspective for the 2019-2020 school year. Four multidisciplinary groups were created, and each group made a proposal for an educational innovation project with a gender perspective considering the fundamental elements of the coeducational practices worked on during the workshop.

\section{FRAMEWORK FOR GENDER PERSPECTIVE IN ENGINEERING}

The inclusion of gender perspective in the teaching and learning engineering is fundamental, due to the society will be affected by the technological solutions designed by engineers, so it is necessary to avoid bias [24]. There are different general frameworks to help into the inclusion of gender perspective in higher education [25, 26, 27]. For example, in the framework proposed by Catalunya (Spain), the gender perspective applied in teaching implies a reflection process on competence and skills in the curriculum and learning outcomes, the design of courses, sex and gender-sensitive contents and examples, inclusive language, gender-balanced bibliography selection, assessment methods, and gender-sensitive teaching methods and inclusive learning environments [25]. In this sense, the present work proposes a framework to include the gender perspective in engineering courses (Fig. 5), although it could be extended to other fields.

Also, it is important the definition of some learning outcomes related to the gender dimension competency. Some general learning outcomes are presented as an example to consider it in the subjects [25]:

- Students can distinguish the effects of the variables of sex and gender in theoretical and empirical analyzes.

- Students can identify the gender studies contributions in their activity.

- Students can produce and analyze results in a gendersensitive way.

- Students can create and use gender-sensitive indicators and metrics (qualitative and quantitative).

- Students can identify gender inequality among other types of inequalities, such as race, disabilities, social class, etc.

- Students can identify and analyze the structural causes and effects of gender violence.

- Students are familiar with and use the female contributions and other gender studies in their disciplines.

- Students identify and can analyze gender roles, stereotypes and bias in their discipline or the exercise of their profession.

- Students use inclusive and non-sexist language in their reports and presentations.

- Specifically, as learning outcomes of Information and Communication Technologies and Computer Science we can mention the following:

- Students consider and pay attention to the differences among the target users taking into account gender/sex.

- Students are aware of differences between users according to their gender in access to and the use of hardware and software.

- Students are aware of the importance of gender in the design of user interfaces and user experience. 


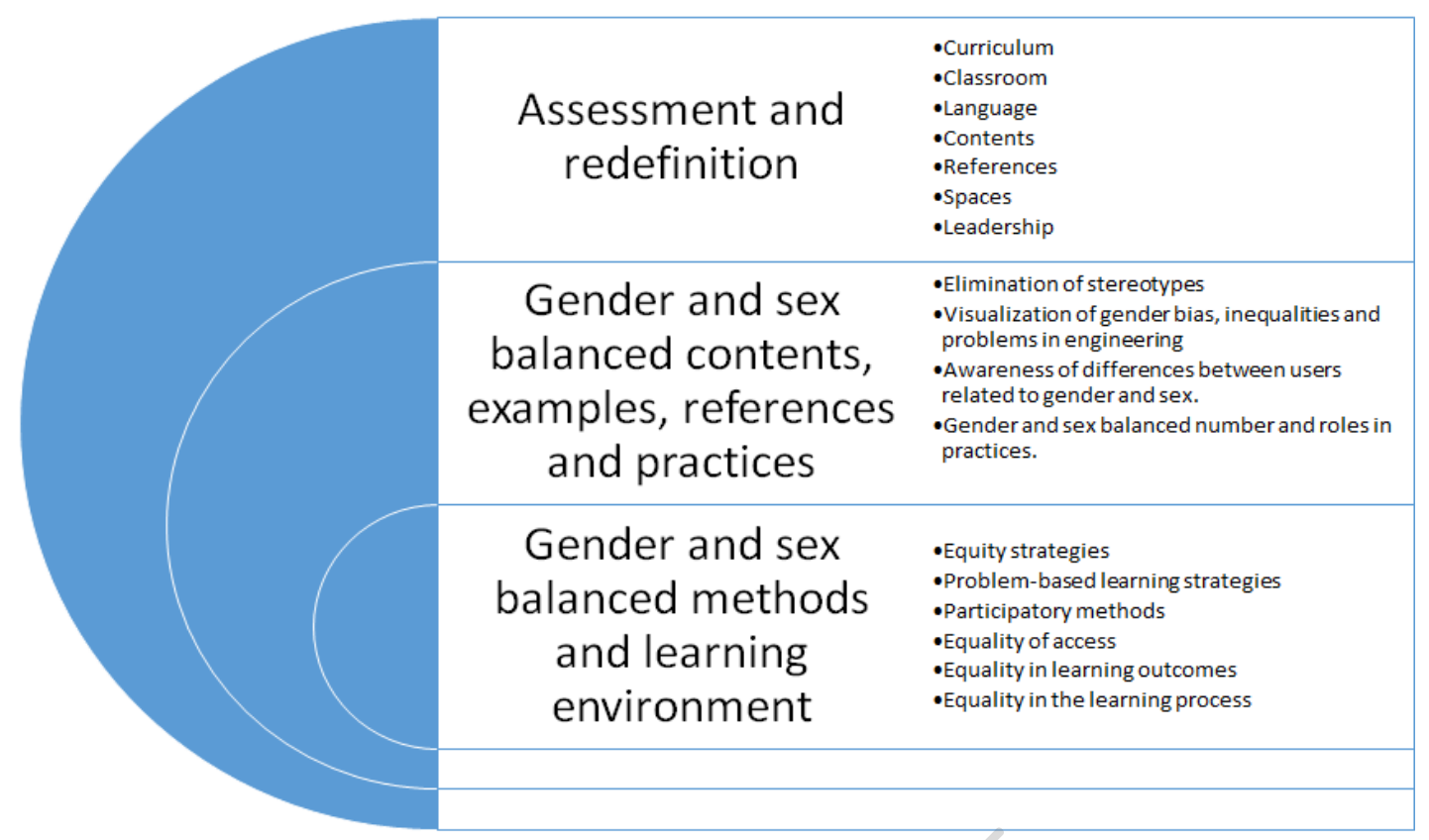

Fig. 5. The framework to include the gender perspective in engineering courses.

\section{CONCLUSION}

There is a considerable amount of initiatives facing the gender gap before university studies and during professional life, but there is a lack of interventions during the university stage. Moreover, there are many proposals and studies focused on co-education at all educational levels, but there are practical works particularly focus on engineering. In this paper, guidelines and elements for the design of coeducational experiences for university teaching were presented and also a practical framework to include the gender perspective in engineering courses.

The framework was developed in two phases, firstly, different educational innovation projects were developed using different strategies and after, a co-creation workshop was carried out with teachers who applied a self-diagnosis technique in their own practices. The instruments used in the workshop was a Canvas model for the design and a rubric for the assessment of their practices. Consequently, a set of recommendations emerged, and they were organized into a framework to include the gender perspective in an engineering course. This framework is composed by different dimensions:

a) The assessment and redefinition of key elements in teaching, like the curriculum, classroom, language, contents, references, organization of spaces and gender-balance roles and leadership.

b) Gender and sex balanced contents, examples, references and practices that ensure the elimination of stereotypes, promoting the awareness of gender bias and inequalities.

c) Gender and sex balance methods and learning environment to ensure the equity strategies, active methods and equality in the access, learning outcomes and learning process.

Across the definition of the framework, some problems emerged in each phase. First, during the implementation of the educational innovation projects, there was an important issue in the experience carried out in Software Engineering course, several students were against introducing the gender perspective as part of software engineering and they carried out some actions to invalidate the pilot [18]. Regarding the second phase, some challenges were faced with the participants of the workshop, not specially related to the instruments used, but to some participants' attitudes to change in their subjects. In particular, most of the barriers to change were with the male participants with an engineering or science background.

The main limitations of this work are that authors have worked with only two Spanish universities and the workshop was developed with a small sample of teachers of the University of Salamanca. So, it is not possible to generalize the results. Consequently, as future work, it is planned to extend the validation phase of the developed instruments and framework with other higher institutions in Spain and also from different countries.

The framework proposed in this work provides a set of practical guidelines and a set of tools that can be directly used by the engineering professors to transform their subjects from a co-educational point of view.

\section{ACKNOWLEDGMENT}

This work has been possible with the support of the Erasmus+ Programme of the European Union in its Key Action 2 "Capacity-building in Higher Education". Project W-STEM "Building the future of Latin America: engaging women into STEM" (Reference number 598923-EPP-1-2018-1-ESEPPKA2-CBHE-JP). The content of this publication does not reflect the official opinion of the European Union. Responsibility for the information and views expressed in the publication lies entirely with the authors.

\section{REFERENCES}

[1] DigitalES. "El desafío de las vocaciones STEM.Por qué los jóvenes españoles descartan los estudios de ciencia y tecnología," 2019. 
[Online] Available: https://www.digitales.es/wpcontent/uploads/2019/09/Informe-EL-DESAFIO-DE-LASVOCACIONES-STEM-DIGITAL-AF-1.pdf

[2] R. Colomo-Palacios, N. Ben Yahia, and X. Larrucea, "Gender diversity among computing students: reflections from Norway, Spain and Tunisia," in Proceedings of the 7th International Conference on Technological Ecosystems for Enhancing Multiculturality (TEEM 2019) (León, Spain, October 16-18, 2019), M. Á. Conde-González, F. J. Rodríguez Sedano, C. Fernández Llamas, and F. J. García-Peñalvo Eds. New York, NY, USA: ACM, 2019, pp. 196-200.

[3] M. I. Menéndez Menéndez, "Metodologías de innovación docente: la perspectiva de género en Comunicación Audiovisual," Historia y Comunicación Social, vol. 18, pp. 699-710, 2013, doi: 10.5209/rev_HICS.2013.v18.44000.

[4] E. Bosch Fiol, V. A. Ferrer Pérez, and V. Ferreiro Basurto, "Incorporación de los contenidos en igualdad de oportunidades y género en grado," in Actas del I Congreso Internacional de Educación para la Igualdad, F. J. del Pozo Serrano, M. M. Jiménez Ramírez, M. S. Entrena Jiménez, and R. A. González Puntas Eds. Granada: Natívola, 2011, pp. 55-65.

[5] C. S. González-González, A. García-Holgado, F. J. García-Peñalvo, and J. Mena, "Towards equality in higher education: Innovative Teaching experiences in computer education," in Proceedings of the XIX International Conference on Human Computer Interaction, C. Manresa-Yee and R. Mas Sansó Eds. New York, NY, USA: ACM, 2018, p. article 42.

[6] J. R. Guijarro-Ojeda, C. Pérez Valverde, R. Ruiz Cecilia, A. B. Garcia Berben, and M. A. Ramírez Castillo, "The Gender Perspective in Teacher Education: Innovating Through Psychological and Cultural Discourses," The International Journal of Interdisciplinary Social Sciences: Annual Review, vol. 2, no. 2, pp. 431-438, 2007, doi: 10.18848/1833-1882/CGP/v02i02/52288.

[7] J. J. Good, J. A. Woodzicka, and L. C. Wingfield, "The effects of gender stereotypic and counter-stereotypic textbook images on science performance," The Journal of social psychology, vol. 150, no. 2, pp. 132-147, 2010.

[8] S. Kulturel-Konak, M. L. D'Allegro, and S. Dickinson, "Review of gender differences in learning styles: Suggestions for STEM education," Contemporary Issues in Education Research (CIER), vol. 4, no. 3, pp. 9-18, 2011.

[9] A. L. Pawley, C. Schimpf, and L. Nelson, "Gender in engineering education research: A content analysis of research in JEE, 1998-2012," Journal of Engineering Education, vol. 105, no. 3, pp. 508-528, 2016.

[10] R. Strachan, A. Peixoto, I. Emembolu, and M. T. Restivo, "Women in engineering: Addressing the gender gap, exploring trust and our unconscious bias," in 2018 IEEE Global Engineering Education Conference (EDUCON), (17-20 April 2018, Santa Crúz de Tenerife, Canary Islands, Spain). USA: IEEE, 2018, pp.2088-2093.

[11] C. Bieri Buschor, S. Berweger, A. Keck $\wedge$ Frei, and C. Kappler, "Majoring in STEM - what accounts for women's career decision making? A mixed methods study," The Journal of Educational Research, vol. 107, no. 3, pp. 167-176, 2014.

[12] A. Kolmos, N. Mejlgaard, S. Haase, and J. E. Holgaard, "Motivational factors, gender and engineering education," European Journal of Engineering Education, vol. 38, no. 3, pp. 340-358, 2013.

[13] O'Brien, L. T., Blodorn, A., Adams, G., Garcia, D. M., \& Hammer, E. (2015). Ethnic variation in gender-STEM stereotypes and STEM participation: An intersectional approach. Cultural Diversity and Ethnic Minority Psychology, 21(2), 169.
[14] A. Peixoto et al., "Diversity and inclusion in engineering education: Looking through the gender question," in 2018 IEEE Global Engineering Education Conference (EDUCON), (17-20 April 2018, Santa Cruz de Tenerife, Canary Islands, Spain). USA: IEEE, 2018, pp. 2071-2075.

[15] J. Peters, "Designing inclusion into engineering education. A fresh, practical look at how diversity impacts on engineering and strategies for change," Royal Academy of Engineering, London, UK, 2018. [Online]. Available: https://www.raeng.org.uk/publications/reports/designing-inclusioninto-engineering-education

[16] J. Mills, M. Ayre, and J. Gill, Gender Inclusive Engineering Education. New York, USA: Routledge, 2010.

[17] A. García-Holgado et al., "Estudio piloto sobre la percepción de la brecha de género en estudios de ingeniería informática," in Aprendizaje, Innovación y Cooperación como impulsores del cambio metodológico. Actas del V Congreso Internacional sobre Aprendizaje, Innovación y Competitividad. CINAIC 2019 (9-11 de Octubre de 2019, Zaragoza, España), M. L. Sein-Echaluce Lacleta, Á. Fidalgo Blanco, and F. J. García-Peñalvo Eds. Zaragoza, Spain: Servicio de Publicaciones Universidad de Zaragoza, 2019, pp. 698-703.

[18] A. García-Holgado, J. Mena, F. J. García-Peñalvo, and C. S. González, "Inclusion of gender perspective in Computer Engineering careers: Elaboration of a questionnaire to assess the gender gap in Tertiary Education," in 2018 IEEE Global Engineering Education Conference (EDUCON), (17-20 April 2018, Santa Cruz de Tenerife, Canary Islands, Spain). USA: IEEE, 2018, pp. 1547-1554.

[19] A. Vega Navarro et al., "Una experiencia de innovación en los procesos de enseñanza-aprendizaje desde la perspectiva de género," in $D e$ la innovación imaginada a los procesos de cambio Servicio de Publicaciones de la ULL, 2018, pp. 177-200.

[20] C. S. González, A. García-Holgado, and F. J. García-Peñalvo. "Introduciendo la perspectiva de género en la enseñanza universitaria: co-creación de guías docentes y proyectos de innovación", in IX Jornadas Internacionales de Campus Virtuales (JICV'19), September 2019, Popayan, Colombia.

[21] C. S. González-González and A. García-Holgado, "Model Canvas for the design of co-educational practices and rubrics for their assessment," 2019. [Online]. Available: http://shorturl.at/IEPUW.

[22] I. Carraza Estévez et al., Breve Diccionario Co-educativo. Principado de Asturias, Spain: Consejería de Educación y Ciencia, 2008.

[23] "Repositorio documental de la Universidad de Salamanca GREDOS." https://gredos.usal.es/ (accessed 28 December, 2019).

[24] C. S. González et al., "Gender and Engineering: Developing Actions to Encourage Women in Tech," in 2018 IEEE Global Engineering Education Conference (EDUCON), (17-20 April 2018, Santa Cruz de Tenerife, Canary Islands, Spain). USA: IEEE, 2018, pp. 2082-2087.

[25] AQU Catalunya. "General General framework for incorporating the gender perspective in the higher education teaching," 2019. [Online]. Available: http://www.aqu.cat/doc/doc 21331700 1.pdf

[26] UNESCO. "From gender studies to gender IN studies. case studies on gender-inclusive curriculum in higher education," 2011. [Online] Available: https://unesdoc.unesco.org/ark:/48223/pf0000211180 eng

[27] USAID. "Gender equality framework," 2018. [Online]. Available: http://shorturl.at/bklCR 